\title{
Serine/Threonine-Protein Kinase DCLK1
}

National Cancer Institute

\section{Source}

National Cancer Institute. Serine/Threonine-Protein Kinase DCLK1. NCI Thesaurus. Code C158674.

Serine/threonine-protein kinase DCLK1 (740 aa, $~ 82 \mathrm{kDa}$ ) is encoded by the human DCLK1 gene. This protein is involved in neurogenesis, neuronal migration, microtubule polymerization and retrograde transport. 